Portland State University

PDXScholar

6-1-1967

\title{
Thermal and Electrical Resistance of Metal Contacts
}

Roland E. Ott

Portland State University

Follow this and additional works at: https://pdxscholar.library.pdx.edu/open_access_etds Let us know how access to this document benefits you.

\section{Recommended Citation}

Ott, Roland E., "Thermal and Electrical Resistance of Metal Contacts" (1967). Dissertations and Theses.

Paper 325.

https://doi.org/10.15760/etd.325

This Thesis is brought to you for free and open access. It has been accepted for inclusion in Dissertations and Theses by an authorized administrator of PDXScholar. Please contact us if we can make this document more accessible: pdxscholar@pdx.edu. 

for the $\frac{M S}{\text { in Applied Sclence }}$

Date thesis is presented June 1967

Title Thermal and Electrical Resistance of Metal Contacts

Abstract approved

In engineerins practice it is important to know which factors affect the thermal and electrical resistances of metal contacts. This thesis is to investigate some of these factors such as surface roughness and contact presiure. Thermal-electrical contact resistance ratios for metal contacts were calculated from the experimental data.

The technical literature was searched, and several pagers were found in which either thermal or electrical contact resistance was studied separately. However, none of the papers recorded data for both thermal and electrical resiatances for the same samples.

The information found in these papers has been used as a background for understanding the nature of thermal and electrical contact resistance.

Both of these contact resistances are primarily a function of the load on the contact and the condition of the surfaces. At low pressures only a small fraction of the total gross area of the contacts is in metalto-metal contact. Increasing the load, flattens the "hills" and reduces both the therial and electrical contact resistance. This phenomenon is called "spreading resistance" since the flow of heat or electrical current must apread out after they pass through the restricted areas that are actually in contact.

Another type of thermal and electrical resistance, which is called "Interface resistance", is caused by a film of forelgn material such as an oxide, etc. On the surfaces of the contacting "bills".

If the space between the "hills" of a contact is filled with air, there is a heat flow by convection currents. The literature indicates this quantity of heat flow is approximately one thousandth of the total heat flow through metal contacts.

Since the only electrical current conduction mechanism acting between areas not in actual metellic contact is that due to thermionic emission, the electrical resistance for these areas will be extremely high at room temperature for which thermionic emisston is negligible.

The experimental apparatus to measure both the thermal and electrical contact reslstances consists mainly of a bellows-actuated press which is 
operated remotely under a vacuum bell. The press pressure loads the sample metal wafers. A thin-f1lm heat meter is used to indicate the quantity of heat flowing through the metal contacts. The temperature drop caused by the contacts is measured with thermocouples. The temperature difference and the quantity of heat flowing is used to caleulate the thermal contact resistance. A strain gage on the bellows-press stem measures the loading on the contact surfaces. Electrical probes are used to measure the electrical resistance across the contact surfaces.

The thermocouples and electrical resistance probes are permanently installed in the outer two smooth copper wafera. This makes it possible to quickly change to other sets of sample wafers of other metals and finishes.

In order to use this permanent arrangement, it is necessary to finish two mating surfaces of the particular set of metal wafers to be tested, similar to the permanent smooth copper wafers so that these two extra mating contact resistances can be found and thus be subtracted from the overall contact resistance.

The data indicates that the thermal-electrical contact resistance ratio can be changed by changing the load on the contacts.

The heat meter has performed very well, and this new method of measuring heat flow will undoubtedly become a standard method of measuring heat flux. 
THERMAL AID ELECTRICAL RESISTANCE

OF METAL CONAACIS

by

ROLAND E. OTI

\author{
A THESIS \\ submitted to \\ PORTIAND STATE COLLEGE
}

In partial fulfillment of

the requirements for the

degree of

MASTER OF SCIERCE

June 1967 


\section{APPROVED}
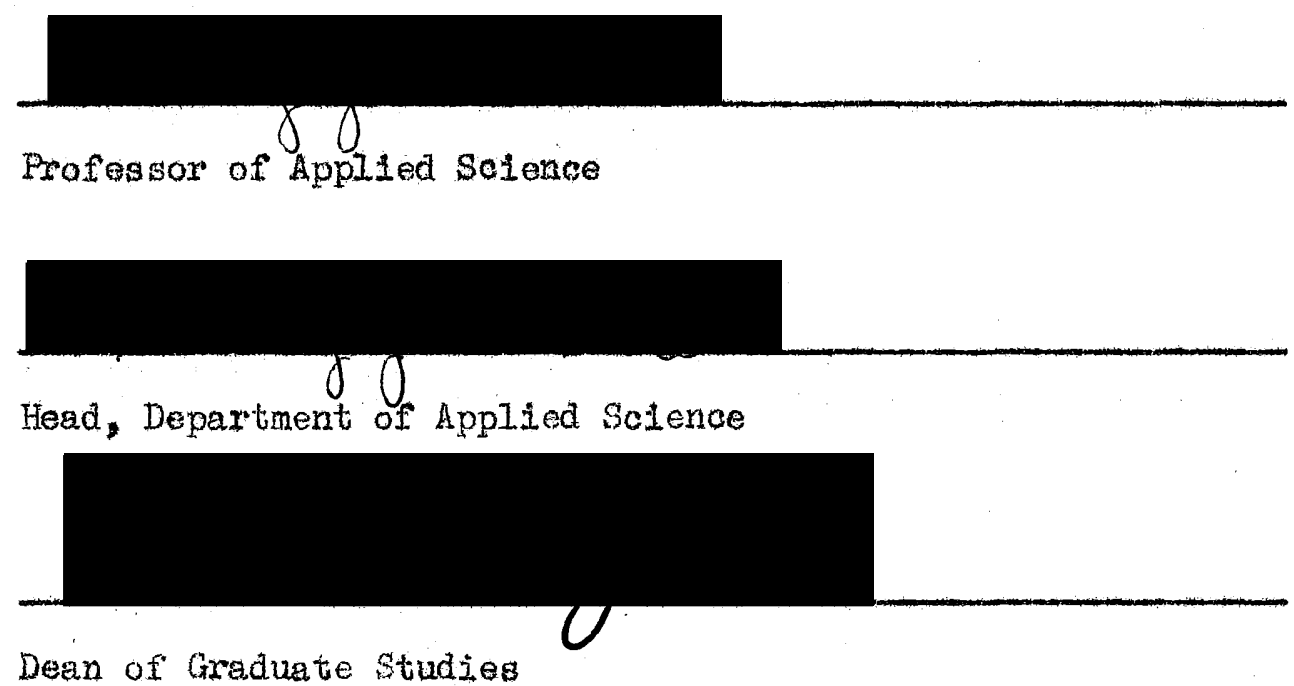

Date thesis is presented Mey 25, 1967

Typea by Judith E. Sheetz 


\section{ACKNOWLEDGMENT}

In preparation of this thesis, Dr. Harry J. White and Mr. James W. Combs of Portland State College and Mr. Paul Stangeland of the U. $\mathrm{S}$. Army Corps of Ingineers, Portland District, gave me encouragement.

Mr. N. E. Hager, Jr. of the Armstrong Cork Conpany provided a sample heat meter which was very vital to the experiment.

Mr. Michael Tierney of BLH Electronics supplied sample strain gages and information on how to apply the gages.

Mr. Jack Janacek, Head of the Portland State College machine shop, has been extremely helpful in his efforts to put together the bellows press assembly.

My wife, Bethine, has encouraged me and has been very patient all during the several years I have been engaged in this graduate study. 
TABIE OF CONLFNTS

Chapter

Page

1 Introduction 1

2 Thermal Resistance of Metal Contacts 3

3 Electrical Resistance of Metal Contacts 7

4 Measurement of Thermal and Electrical Resistance of Metal Contacts. 14

5 Conclusions 20

Recommendations $2 I$

Bibllography 22

Appendix A - Description of Instruments 23

Appendix B - Sample Calculations 24

Appendix C - Table 1, Surmary of Ratios of Thermal to Electrical Contact Resistance

26

Appendix D - Photographs of Apparatus $\quad 27$

Appendix E - Graphs 29 


\section{CHAPTER 1}

\section{IMRODUCIION \\ THERMAL AND ELECTRICAL RESISTANCE \\ OF METAI CONACTS}

Numerous situetions arlse in engineering practice in which it is important to know the thermal and electrical resistances at the junction of two dry metal surfeces. Also it is helpful to know how the contact resistances are affected by the condition of the surface, the applied pressure between the surfaces and the temperature.

Electrical failures on clamped jolntg are due to high contact resistance. With sufflcient electrical current flowing, the power loss at the contact may cause high temperatures if sufficient heat is not carried away. The effect of high temperature is to produce oxidation which in turn increases contact resigtence.

The problem of thermal and electrical contact resistance is very important in the operation of solid state devices which are fabricated with dry contects. These are joints that are not welded or soldered. but which must dissipate heat and also carry electrical current. The purpose of this investigation is to shed ame light on the themal-electrical contact resiatance ratios for metal contacts. The ratios that are established for metal contacts under certain surface conditions and mating pressures can be used to establish the expected thermal conductivity for a particular device by observing the electrical contact resistance only. Th1s would be an advantage since 
electrical resiotances can be measured more easily than thermel resistance in completed device with metal surfaces in contact with each other.

I searched the 1iterature and found several papers in which thermal contact resistance or electrical contact resistance experiments were described. However, none of the articles included measurement of both the thermal and electrical contact resistances on the same samples. The Information found in these papers has been used as a background to describe the thermal and electrical contact resistance processes. The values that were reported in the articles has served as a basis for estimating what data may be expected from my thesis experiment.

In order to study both of the contact resistances simultaneously, it was necessary to load the contact surfaces. This was accomplished with a bellows press which used nitrogen gas pressure to load the metal contact surfaces. A thermoelectric-type of thin-foll heat moter was placed in series with the metal wafers to measure the hest flow across the contacts. Thermocouples Indicated the temperature arop across the metal contacts. A strain gage on the stem of the press was used to Indicate the loading between the contacts. Potential type of instruments were used to measure the electrical resistance between the contacts. The whole assembly was placed in the bell jar of a vacuum system in order to prevent thermal convection currents. 
CHAPTER 2

THERMAL RESISTANCE OF

METAL CONIACIS

There is a close analogy between the thermal and electrical jointconductance mechanism. The concept of spreading resistance developed through study of electrical contacts is adapted to the interpretation of the behavior of thermal resistance presented by a joint between metal surfaces in a thermal circuit. (12, p. 259)

Data from the references has shown that thermal contact resiatance of joints is primarily a function of the load on the contact surfaces. It is possible, at sufficiently high pressures or for sufficlently smooth and flat surfaces for a very large percentage of the surface aree of each contact face to be in actual metrl-to-metal contact with the other. The thermal resistance of the joint then would be consldered to be approxinately equel to zero. (12, p. 259)

At low pressures the areas are in metal-to-metal contact over only a small fraction of the total gross contact area. The actual contact area is made up of a large number of separate "hills" or "points" distributed randomly. It is assumed that if a vacuum or even air fills the "void" spaces between the actual contact areas, the majorlty of the heat flows through the metal-to-metal "hills" since there is such a hlgh resiatance to heat flow through the afr path or a vacuum. The thermal conductivity through an fir film is about one thousandth of 
that through the actual metal in contact. It should be mentioned, bowever, that if hydrogen or helium gas fllled the "vold" spaces between the actual contact areas, the convection heat flow through these gases would be approximately six times that expected through an air f11m.

The resistance to heat flow mainiy associated with metal contacts can be discussed with the use of the concept of spreading resistance. In this concept, the "IInes" of heat flow must "fan out" or "spread out" after passing through the points of actual contact. Since these contact areas are relatively small compared to the overall area of the surfaces, the heat flux is very great at these points. Also the heat must flow latterally at the surface to reach the contact points. As a load is applied to the contacts, the projecting "hills" start to flatten out and a larger total area is available for conducting heat. The rougher the surfece, the greater will be the effect on the thermal contact resistance by increasing or decreasing the load. The preaence of an oxide film or other forelgn material of low thermal conductivity also contributes to the thermal resistance of the joint. However, except at very low pressures, the oxide resistance appears to account for only a amall part of the total thermal contact resistance. (12, pp. 259-260)

The conclusions and results of three thermel contact resistance experiments obtained from the Iiterature are included in this thesis 
In order to establish some qualitative basis for indicating the important factors in the measuring of thermal contact realatance.

Wellls and Ryder came to the following conclusions based on their experimental observations: (12, p. 266)

1. The thermal conductance of a dry joint increases with pressure, linearly for steel, and generally exponentially for aluminum and bronze.

2. The thermal resistance of dry joints decreases with a decrease In the roughness of the surfaces.

3. At a given temperature, pressure, and roughness, the thermal resistance of dry joints decreases in the order of steel, bronze and aluminum.

4. The thermal resistance of a dry joint decreases as the temperature increases.

Jacobs and Starr found the following results: (6, p. 141)

1. After studying copper, gold and silver contacts in a vacuum they found that only in the case of copper does the conductance vary Inearly with contact pressure. (The maximum pressure was approximately $2.5 \mathrm{~kg} / \mathrm{cm}^{2}$.)

2. They found that the thermal conductance was approximately the same when the surfaces were "Just touching" or separated by a few milimeters. This radiation conduction is less than $10^{-3}$ watt $/ \mathrm{cm} /{ }^{\circ} \mathrm{C}$.

3. In all cases the thermal conductances are much smalier at the lower temperatures. This is probably due to adsorbed surface films. (The experiments were conducted at $25^{\circ} \mathrm{C}$ and $-195^{\circ} \mathrm{C}$ ) 
Kouwenhoven and Potter experimented with steel samples and arrived at the following conclusions: $(9, p, 520-5)$

1. Thermal resistance decreases with pressure in a menner which is essentlally exponential. The rate of decrease is greater for rougher surfaces. For very smooth specimens the thermal reststance is practically independent of pressure.

2. The inconsistencles and insufficiency of the data make it impossible to predict absolute values of thermal resistance for given roughness and pressures. It is probable that for heat flow measurements the rms. system of designating roughness is inadequate.

3. At constant pressure and in the absence of corrosion, thermal resistance is substantially constant as temperature level is incressed.

4. There is need for more accurate knowledge of the actual surface areas in contact as this remains one of the greatest unknown factors in the problem.

There is generally good agreement between the reported results of the three groups of thermal contact resistance experiments. One noticeable exception, however, is the conclusion by Weills and Ryder who found that the thermal contact resistance of a steel joint decreases linearly with pressure (reported as thermal conductance of a dry joint increases with pressure); whereas Kouwenhoven and Potter stated that the thermal resistance decreasea essentially exponentially for a steel joint. 
CHAFTER 3

FIECTRICAI RESISTANCE OF

METAL COIVTACTS

Electrical contact resistance is a very extensive subject, including a wide variety of incidental phenomena, such as thermal effects, coherer action and the behavior of different kinds of surface f1lms. A truly comprehensive treatment of electrical contact phenomena would necessarily include the Peltfer, Seebeck and Thomson effects as well. However, these three effects belong to the domain of thermoelectricity rather than to electrical contact theory. For a general background, the review of electrical contact resistance can be found. in an article by G. Windred. (13, p. 547)

The four main factor that determine electrical contact resistance as follows:

1. The kind of materials used for each contact

2. The condition sind roughness of the surfaces

3. The shape of the contact surfaces

4. The mechanical pressure acting between the contacts (13, p. 550$)$

In regard to materials, it has been found in general that materials of high electricel conductivity, such as silver and copper, give lower electrical contact resistances than those materlals of lower electrical conductivity, such as Iron and tungsten. (13, p. 550) 
A metal surface, even finished to optical flatness, has many points that protrude. Thus, if two of these metal surfaces are brought together under very low pressure, isolated points on the surfaces will touch. An electricel current will encounter a higher resistance at these restricted points. In addition to a greatly increased currenc density, the constriction of the lines of current flow also causes a lengthening of these lines and thus causes what is known as "spreading resistance", $R_{g}$, between the contacts. If the contact surfaces are not perfectly clean, there is also an "Interface reslatance", $R_{1}$, caused by oxide or gas films. The total contact resistance, $R_{c}=R_{g}+R_{1}$ * $(8$, p. 458-8)

As the load on the contacts is increased, the "hills" between the contacts are deformed more and more until the surface areas are more nearly ated. The maximum pressure that a given material can withstand without irreversibly deforming is based on the hardness or yield point in compression, $\mathrm{H}$, measured in psi. If $\mathrm{S}_{\mathrm{b}}$ equals the loadbearing-contact area in square inches, we may write for ordinary flat surface contacts that $S_{b}=2 F / H$. (The force, F, is measured in pounds.) Whenever plastic deformation or splintering of some of the "hills" in a contact takes place, then additional subareas are brought into contact. When the force is applied a second time, this new contact pattern will cause a change in the electrical resistance. ( 8 , p. 458-s)

In addition to the path of electrical current through the "h1IIs" of a contact, there is another possible path of current flow that 
should be considered. This path is across the "gap" between the contacts. This electric current would be carried by electrons that can surmount the distance between the contact surfaces. However, at ambient temperatures a sufficlent number of electrons do rot have enough energy to carry any appreciable current since the "gop" between the non-touching parts of the surfaces is too great. Even polfshed surfaces, flat to a quarter wave length of light, still have "hills" and "valleys" of over a hundred Angstrom Units, \&. (8, p. 458-s)

The h1gh resistance of a "gap" between metal surfaces has been studied by $J$. Frenkel. For a "gap" of $10 \AA$ and a mean free path of electrons of length approximately equal to $100 \AA$ (which roughly corresponds to the mean free path of electrons at room temperature) the resistance of the contact per unit surface area (in $\mathrm{cm}^{2}$ ) 18 of the order of $10^{-2}$ ohms. For a "gap" twice as large, or 20 , the resiatance is about $10^{8}$ ohms. Further increases in the "gap" would mean practicaliy no flow of electrical current. For a "gap" of $20 \mathrm{~A}$, it would require an electric field of 10 million volts per cm across the "gap", corresponding to a potential afference of 2 volts, to obtain a current of the order of $10^{-8} \mathrm{amp} / \mathrm{cm}^{2} . \quad(4, \mathrm{pp} .1610,1611)$

Since the "gaps" normally encountered in metal contacts are greater than $100 \AA$, any thermionic current between the contacts can be neglected at amblent temperatures. Thus, it is assumed that at amblent temperatures all measurable electrical current flows through the actuel contact "h111s" and the flim on these "h1lls". (At h1gh 
temperatures thermionic emmission of electrons would carry part of the electrical current.)

The rebults and conclusions of three electrical contact resistance experiments obtained from the literature are included in this thesis in order to establish a qualitative basis for indleating the Important factors in the measuring of electrical contact resiotance.

Kouwenhoven and little found the following results: $(8$, p. 464-s)

1. The value of spreading registance can be effectively controlled by varying the number of contact subareas, " $n$ ". They found for the materials tested (silver, aluminum, bronze and bress) that for "n" equal to about 3000 (approximately 15,000 for a contact of one square Inch in area) the value of $R_{B}$ becomes less than one micro-obm, and effectively diseppears, being negligible compared to $R_{1}$. The load on the one-half Inch diameter specimens was 230 pounds or more.

2. For thin surface f1lms, the interface resistance, $R_{1}$, may be controlled by varylng the load on the contacts. $R_{1} 18$ independent of the contact patterm.

3. Increasing the force on the contacts w1ll reduce both the spreading and interface resiatance.

G. Windred reported the results of Dr. Hoerhard Contius's dissertation on the influence of the magnitude of pressure and surfece upon electrical contact resistance. (The orlginal paper was published in Dresden in 1929.) Some of the conelusions made by Dr. Contius are summarlzed as follows: (13, Pp. 577, 579, 581) 
1. In the case of pointed contacts the pressure and resistance are related in accordance with the formula $R=k /(P)^{l / 2}$. The actual or effective contact surfece approximates closely to the apparent surface.

2. Contact between plane surfaces is formed by the aggregate of several points of contact, the number and size of which depend upon the applied pressure and the surface condition. Pressure and resistance are related by the formula $R=k / p^{n}$, where the exponent $n$ depends upon the nature of the surfaces. In the case of accurately ground and pollshed surfaces, $n=2$. With increasing pressure approaching the yleld point of the entire contact, the value of a changes gradualiy to 1/2. $P$ is given In kilograms and $R$ in ohms. (See Table I for values of conatant, k.)

3. Particularly smooth surfaces are characterised by high contact resistance. If, however, the surfaces are very rough, the conditione become similax to those of pointed contacts.

4. In the case of ground and smooth surfaces the contacts of large area have a higher resistance than the smaller ones. In the case of normally finished surfaces there is no appreciable difference in this respect.

A portion of Table I, "Relation Between Contact Resistance and Pressure (E. Contius)": 


\begin{tabular}{|c|c|c|c|}
\hline \multirow{2}{*}{ Type of Contact } & \multirow{2}{*}{ Conditions } & \multicolumn{2}{|c|}{$\begin{array}{c}\text { Values of } n \text { and } \\
k \text { in Resistance } \\
\text { Formula } \\
R=k / P^{n}\end{array}$} \\
\hline & & & \\
\hline $\begin{array}{l}\text { Polnt-polnt } \\
\text { Polnt-polnt } \\
\text { Plane, } 1.6 \mathrm{~cm}^{2} \\
\text { Plane, } 0.8 \mathrm{~cm}^{2} \\
\text { Plane, } 1.6 \mathrm{~cm}^{2} \\
\text { Plane, } 3.2 \mathrm{~cm}^{2} \\
\text { Plane, } 1.6 \mathrm{~cm}^{2}\end{array}$ & $\begin{array}{l}\text { Theoretical } \\
\text { Empirlcal } \\
\text { Normal finish } \\
\text { Ground, new } \\
\text { Ground, new } \\
\text { Ground, new } \\
\text { Ground, much used }\end{array}$ & $\begin{array}{l}1 / 2 \\
1 / 2 \\
1 \\
2 \\
2 \\
2 \\
5 / 3\end{array}$ & $\begin{array}{l}0.000204 \\
0.000230 \\
0.000430 \\
0.010000 \\
0.050000 \\
0.400000 \\
0.001900\end{array}$ \\
\hline
\end{tabular}

G. E. Luke reported the following: (10, p. 68)

1. With respect to temperature, the contact resistance of the metals varled; thus, some teats were made with copper in which the contact resistance was slightly decreased with increasing temperatures. This would indicate a negative temperature coefficient. This was verIfled by teats on the resibtance of copper oxide, which had apectic resistance of 39,400 ohme per inch cube at zero degrees $\mathrm{C}$ and 2160 ohms per inch cube at 100 degrees $c$. The contact resistance of brass and Iron Increased very slightly with increased temperatures.

2. Based on a large number of tests on large copper bus-bars, it has been stated that the contact resistance is Inversely proportional to the pressure. Thus, $\mathrm{RP}^{\mathrm{P}}=0.0008$ to 0.0016 for a cleaned copper surface where $R$ is the contact resistance in ohms and $P$ is the pressure in points. This equation says that the resistance of such a contact is independent of the area of contact and depends only upon the total pressure applied. Thus, for a pressure of 1000 1bs. per square Inch, the contect resistance given by luke is 0.9 micro-ohms per 
square Inch. Experimental results Indicate that brass and iron do not follow such a simple equation.

There is generally good agreement between the results of the three groups of electrical contact resistance experiments reported by the researchers.

The formula $R=\mathrm{k} / \mathrm{P}^{\mathrm{h}}$ given by $\mathrm{E}$. Contius for normal fintshed. plane contacts somewhat resembles the formula $R P=0.0008$ to 0.0016 given by G. E. Luke. 


\section{CHAPTER 4}

\section{MRASURRMGII OF THERMAL AND EILCTRICAL RESISTANCE OF METAL CONIACTS}

Measurement of the thermal and electrical resistances of metal contaets was accomplished with an apparatus that was operated in a vacuum. Th1s arrangement was used in order to prevent heat flow away from the samples by air convection currents.

A bellows press was used to load the contact surfaces. Thus, the load on the sample metal wafers could be changed from outslde of the vacuum bell by merely changing the nitrogen gas pressure in the belLows.

The bellows press consists of a base with four steel rods which support a steel upper plate to which the bellows is attached. The support rods have a long thread on the upper end in order to permit adjustment of the helght of the bellows assembly. A steel loading stem is connected to the bottom of the bellows and is guided by two plates mounted on the support rods.

A platen is engaged on the end of the loading stem with a ball joint in order to insure that the contact surfaces w111 be loaded evenly, Resistance wire is wound around alot which is cut in the upper platen to provide a source of heat. The lower plate was used to conduct the heat away.

A heat meter, which consists of a thin ribbon of semiconductor material, is mounted in series with the metal wafers. The meter 
measures the heat flow through the contact surfaces of the metal wafers. (A more detalled description of the heat meter will be given later.) The sample metal wafers are placed between the heat meter on the bottom and the upper permanent wafer on the top.

The thermocouples and electrical resistence probes are permanently Installed in the outer two smooth copper wafers. This makes it possible to quickly change to other sets of wafers of other metals and. fin1shes.

Wth the data avallable from the thermal and electrical resistance tests on the single smooth copper surface, it was possible to calculate the thermal and electrical resistances of other metal contacts. To accomplish this, two wafers of each of the brass and steel metals were finished on one side similarly to the amooth copper fintsh and then copper plated. Thls permitted the sets of the other metel wafers to be mated with the permanently installed smooth copper wafers. Since the thermal and electrical resistances across these two outer smooth copper contacts had been calculated, the net contact resistances for the test samples could be determined.

The load on the metal wafers was measured with a BLfl Electronics strain gage cemented to the cteel loading stem of the bellows press, The actual measurement of the heat flow quantity is one of the greateat problems in a thermal contact resistance experiment. The temperature-gradient method has been used extensively in previous experiments; however, this method of measuring heat flow has a posstble source of error. Only a small error in the measurement of the slope 
of the gradient can cause large change in the apparent heat flow, especially if the total temperature difference across the resistance 1s not very great.

In order to insure a more accurate measurement of heat Ilow, I selected a new method of determining heat flow across the metal contacts with the use of a heat meter. This new way to neasure heat flow wa developed by Mr. N. E. Hager, Jr. of the Arnstrong Cork Company. The heat 18 measured with a "Thin Foll Heat Meter".

The heat meter used in this experiment consists of a thin-foil differential thermocouple which measures the temperature difference between the two faces of a thin electrical insulator. It is an absolute instrument; 1.e., Its calibration factor can be calibrated as a function of temperature from the physical and geometrical parameters of the film and the thermocouple materials, and no costly experimental calibration is needed. The particular heat meter used is rated within $\pm 5 \%$ accuracy. The device is found to settle to a atable reading in less than $0.5 \mathrm{sec}$. The meter has negliglble thermal resistance, and Its presence does not upset the thermal field under study. These advantages are obtained at the expense of obtaining a very small emf with normal environmental heat fluxes. But the electrical resistance of the meter is so low that good readings can be obtained with modern microvoltmeters. Heat fluxes as low as 0.05 Watts $/ \mathrm{m}^{2}$ have been detected with 2 second response. (5, p. 1565)

The metal wafers are $1 / 8$ inch thick $(0.3775 \mathrm{~cm})$ and $9 / 16$ inch in diameter $(1.42875 \mathrm{~cm})$. The wafers were mede this particular diameter 
so that their area would be equal to $1.6 \mathrm{~cm}^{2}$. The area of $1.6 \mathrm{~cm}^{2}$ was used for contact resistance experiments whlch were conducted by $\mathrm{E}$. Contius. He developed some relationships between electrical contact resistance and the loading between metal contacts.

Three sets of wafers were finished to a smooth surface by first using a \#400 fine grade sandpaper and then polishing them with Crocus cloth. The other three sets of wafers were finished with a No. 80 , rough emery cloth. Care taken to keep the surfaces flat.

The 0.25 inch diameter steel stem permitted a convenfent relationship between the kilograms load and the micro-inch indication on the meter. The strain gage read $7.5 \mathrm{ml}$ cro-inch increments for changes of $5 \mathrm{kJllograms}$ in load.

The vacuum gystem consisted of a mechanical vacuum pump and discharge chamber. Since a very high vacuum was not required, the diffusion pump apparatus was not used. A vacuum was maintained during the tests at approximately $0.5 \mathrm{~mm}$ of $\mathrm{Hg}$.

The electrical potential was measured with a current of 0.035 mp flowing across other metal contacts. This current also produced a voltage drop in the leads as well in the soldered foints. It was necessary, therefore, to determine the voltage drop in the entire external circuit in order to isolate this resistance from the contact resiatance. This loss was measured by soldering a wire between the leads to the permanent copper wafers which acted as the electrical potential probes. These two soldered connections simulated the two soldered connections to the copper wafer probes. The wire was 
measured to equal the lead lengths between these soldered connections and the terminal points at the copper wafers.

Twenty-five different readings were taken at $0.035 \mathrm{ma}, 0.040 \mathrm{ma}$ and $0.045 \mathrm{ma}$. The resistor was changed each time to control the current.

An interesting thing occurred in the process of measuring the current. The milliamp meter had a bent pointer, but It was the only one avallable to me. A thought occurred to me, however, that this bent pointer might be used to advantage. I reasoned that possibly the bent pointer could be used as vernter. This did occur since the bent pointer greduelly covered a meter Indicating mark as it moved very slightly. It gave the appearance of a changing length from very short to a long black IIne. With this arrangement I was able to reproduce readings of the external resistance clrcult with the 50 ma full scale meter to within two-tenths of a mlerovolt plus or minus of the average of all of the readings taken at 0.035 ma. The potentlometer read to tenths of a microvolt.

The electricel sesistance reedinge of the smooth and rough steel samples were taken with no heat gradient since the thermolectric effect of the copper-steel couple vould add a considerable potential to the circult. The electrical resistances of the brass sauples were taken with a heat gradient, but this effect is very minor ince there Is such a small thermoelectric potential difference between copper and brass. This could be considered as a smell source of error for any future experimental work, however. 
The ultimate goal of my experimental work to determine the ratio of the thermal to electrical contact resistance at progressively greater loading of the contacts. The summary of these calculations is given in Table 1, Appenclx C. 
CHAFTER 5

CONCLUSIONS

1. The ratio of thermal resistance to electrical resistance can be changed by changing the force between metal contacts.

2. The therrnal resistance decreases more than the electrical realstances for the same increase in loading.

3. There is a greater change in the ratio of thermal resistance to electrical resistance for smooth copper and smooth brass contacts for a change of load then for rough copper and rough brass contacts for the same change in loading.

4. The electrical resistance of the rough steel contacts was measured to be very much less than that for the smooth steel contacts for the same loading.

5. The apparent increase of the $R_{T} / R_{\text {g }}$ ratio for rough steel at higher loading is based on the large decrease in the measured electr1cal resistance since the thermal resistance continued to decrease at the higher loading.

6. The statement by Kouwenhoven and Potter that the fact that the rate of decrease of thermal resistance for steel with pressure is greater for rougher surfaces is "born out" by Fig. 2 of this thesis. $(9, p \cdot 520-8)$

7. The heat meter has performed very well, and this new nethod of measuring heat flow w1ll undoubtedly become a standard method of measuring heat flux. 


\section{RECOMMENDATIONS}

1. If helium gas could be used to surround the metal contacts, the Increase in the thermel conductance between the contacts could be measured. Also, tests could be run in alr at atmospherlo pressure. These two tests could be compared. with the tests of the contacts in a vacuum. The test in helium should give a gas conductance approximately six times as great as with air between the contacts. The tests In air could be used to check the value, given by Wellis and Pyder, which is about one-thousandth of the total heat that flows through the metal contact.

2. Tests could also be conducted with carbon wafers if one side of two of the carbon wafers were covered with a copper film deposit. This test would indicate the magnitude of non-metal contact resistance.

3. Tests at very low pressures and at higher pressures would give useful data. 


\section{BIBLIOGRAPHY}

1. Brunot, A. W. and Florence F. Buckland. Thermel contact resistance of laminated and machined jolnts. Amerlcan society of mechanlcal engineers transactions. 71:253-257. 1949.

2. Flom, D. G. Contact resistance measurements at low loads. The review of scientific instruments. 29:979-981. 1958.

3. Flom, D. G and R. H. Savage. Insulating films on metal contacts. General electric review. 59-6. 1955.

4. Frenkel, J. On the electrical resistance of contacts between solid conductors. Physical review. 36:1604-1613. 1930.

5. Hager, Nathaniel E., Jr. Thin foll heat meter. The review of scientific instruments. 36:1564-1570. 1965.

6. Jacobs, R. B. and C. Starr. Thermal conductance of metallic contacts. The review of scientific instruments. 10:140-141. 1939.

7. Kisliuk, P, Using contact resistance to messure adsorption of gaser on metals. The Bell system technical journal. 924949. 1958.

8. Kouwenhoven, W. B. and Clarence W. Iittle, Contact resistance. The welding journal. 31:457-\$--464-s. 1952.

9. Kouwenhoven, W. B. and J. H. Potter, Thermel resistance of metel contacts. The welding journal. 27:515-8--520-8. 1948.

10. Luke, George E. The resistance of electrical connections. The electric journal. 21:66-69. 1924.

11. Powell, Robert I. and Arthur A. Aboud. Blectrical contact resistance of copper-copper junctions at low texperatures. The review of seientific instruments. 29:248-9. 1958.

12. We1IIs, N. D. and E. A. Ryder. Thermal resistance measurements of joints formed between stationary metal surfaces. American society of mechanical engineers transactions. 71:259267. 1949.

13. Windred, G. Electrical contact resistance. Journal of the Franklin Institute. 231:547-585. 
APPEIDIX A

DESCRIPTION OF INSTRUMENS

Potentiometer

Leeds and Northrup Company, type K-Z, No. 1133030, used with a standard cell, 1.0185 valts, range $1 \times 10^{-7}$ to 1.6 volts.

Galvanometex

The Faling Corp., "Scalamp", Cat. No. 7891/us, 25 ohms.

Strain Indicator (For SR-4 strain gages)

Baldwin-Iima-Hamilton, Type $\mathrm{N}$, measures in micro-inches.

DC Millianp Meter

Sensitive Research Instrument Corporation, Model "University", Ho. 921548, range 0-50 ma.

Heat Meter

Armatrong Cork Company, No. 61666-D, thin-foll type (area, $\left.1.44 \mathrm{~cm}^{2}\right)$

Vacuum Gage Indicator and Probe

HCR Equipment Corporation, type 701. 
APPENDIX B

SAMPIE CALCULATIONS

\section{At $10 K_{8}$ load for smooth eopper wafers}

$$
\begin{aligned}
& \text { Temp. Diff. }=\frac{(239.0-198.5) 10^{-6} \text { volts }}{43.217 \times 10^{-6} \text { volts per }{ }^{\circ} \mathrm{C}} \\
& =0.94{ }^{\circ} \mathrm{C} \\
& \begin{aligned}
Q=\text { Heat FIOW } & =\frac{21.2 \times 10^{-6} \text { volts } \times 1.44 \mathrm{~cm}^{2} \text { (watts) }}{1540 \times 10^{-6} \text { volts per } \mathrm{cm}^{2}} \\
& =19.8 \times 10^{-3} \text { watts }
\end{aligned}
\end{aligned}
$$

$R_{T C}=$ Thermal contact resistance, $\frac{\mathrm{cm}^{2}-{ }^{\circ} \mathrm{C}}{\text { watt }}$, for one joint of copper $K=Q /$ Temp. Diff.

$$
\mathrm{R}_{\mathrm{TC}}=\frac{1}{\bar{K}}=\left(\frac{\text { Temp. Diff. }}{Q}-\mathrm{R}_{\mathrm{TC}}^{\prime}\right) \frac{1}{7}
$$$$
R_{\mathrm{TC}}=\left(\frac{0.94 \times 1.6 \mathrm{~cm}^{2}}{19.8 \times 10^{-3}}-8.7\right) \frac{1}{7}=\frac{9.6 \mathrm{~cm}^{2}-{ }^{\circ} \mathrm{C}}{\text { watt }}
$$

$R_{T C}^{\prime}=$ Thermal resistance of $\mathrm{s} 1 \times 1 / 8^{\prime \prime}$ thlck copper wafers

$$
\frac{(0.75)(2.54)}{(0.239)(0.92)}=\frac{8.7 \mathrm{~cm}^{2}-{ }^{\circ} \mathrm{C}}{\text { watt }}
$$




$$
\begin{aligned}
& R_{E C}=R-R_{L}-R_{E C}^{\prime} \\
& R=\text { Total measured electrical resistance was measured at } 0.035 \\
& \text { ang } \\
& R_{L}=\text { Electrical resistance of leads to parmanent copper wafer } \\
& \text { probes }=625.0 \times 10^{-6} \text { volts } \\
& \mathrm{R}_{\mathrm{EC}}^{\mathrm{i}}=\text { Electrical resistance of six 1/8" thick copper wafers } \\
& =\left(1.76 \times 10^{-6}\right)(0.75)(2.54)=3.4 \times 10^{-6} \mathrm{obm} / \mathrm{cm}^{2}
\end{aligned}
$$

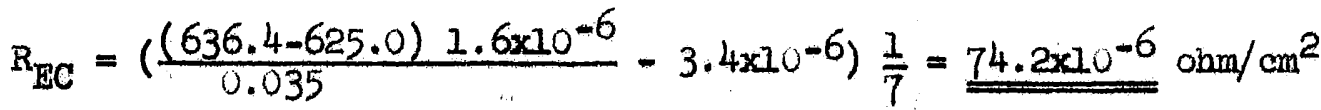

$$
\begin{aligned}
& L=\frac{R_{\mathrm{TC}}}{R_{\mathrm{EC}}}=\frac{9.6}{74.2 \times 10^{-6}}=1.29 \times 10^{5}
\end{aligned}
$$

\section{At $10 \mathrm{~K} 8$ load for rough copper wafers}

Two mating surfaces, of the assembly of the six rough finished copper wafers, were finlshed similarly to the smooth copper wafers; therefore, two of the resistances, calculated for smooth copper contacts, were also subtracted from the total calculated resistances for the rough copper wafers. Th1s left five rough surface contacts.

$$
\begin{aligned}
R_{T C}= & \left(\frac{0.90 \times 1.6}{22.9 \times 10^{-3}}-8.7-2 \times 9.6\right) \frac{1}{5}=\frac{7.1 \mathrm{~cm}^{2}-{ }^{-0} \mathrm{C}}{\text { watt }} \\
R_{\text {EC }}= & \left(\left(\frac{633.0-625.0}{0.035}\right) 1.6 \times 10^{-6}-3.4 \times 10^{-6}-2 \times 74.2 \times 10^{-6}\right) \frac{1}{5}= \\
& 42.8 \times 10^{-6} \\
I= & \frac{7.1}{42.8 \times 10^{-6}}=1.66 \times 105
\end{aligned}
$$

Note: The values for " $L$ " were kept in numerical units only for comparison purposes. 


\section{APPENDIX C}

TABLE 1

SUMMARY OF RATIOS OF THERMAL

TO ELECTRICAL CONIACT RESISTANCE

\begin{tabular}{rrrrrrr}
$\begin{array}{c}\mathrm{K}_{8} \\
\text { Load }\end{array}$ & $\begin{array}{c}\text { Smooth } \\
\text { Copper }\end{array}$ & $\begin{array}{c}\text { Rough } \\
\text { Copper }\end{array}$ & $\begin{array}{c}\text { Smooth } \\
\text { Brass }\end{array}$ & $\begin{array}{c}\text { Rough } \\
\text { Brass }\end{array}$ & $\begin{array}{c}\text { Smooth } \\
\text { Steel }\end{array}$ & $\begin{array}{c}\text { Rough } \\
\text { Steel }\end{array}$ \\
\hline 0 & 2.84 & 2.10 & 3.78 & 3.34 & 0.131 & $* *$ \\
5 & 1.46 & 1.86 & 2.74 & 2.62 & 0.110 & 1.0 \\
10 & 1.29 & 1.66 & 2.50 & 2.41 & 0.124 & 0.87 \\
15 & 1.07 & 1.63 & 2.04 & 2.16 & 0.117 & 0.80 \\
20 & 0.99 & 1.34 & 1.95 & 1.75 & 0.161 & 0.69 \\
25 & 0.94 & 1.17 & 1.84 & 1.55 & 0.192 & 0.72 \\
30 & 0.74 & 1.10 & 1.61 & 1.50 & 0.196 & 0.80 \\
35 & 0.75 & 0.79 & 1.54 & 1.50 & 0.178 & 0.94 \\
40 & 0.66 & 0.88 & 1.41 & 1.32 & $* *$ & $1.59 *$ \\
45 & .63 & 0.81 & 1.55 & 1.31 & $* *$ & $13.38 *$
\end{tabular}

* These ratios were calculated on an observed very low electrical resistance.

* Failed to get a heat meter reading.

*** Falled to get an electrical resistance reading.

$$
R_{T}=\frac{\mathrm{cm}^{2}-{ }^{\circ} \mathrm{C}}{\text { watts }} \quad R_{\mathrm{E}}=\frac{\text { ohms }}{\mathrm{cm}^{2}}
$$

Note: The above ratios are $x 10^{5}$. 


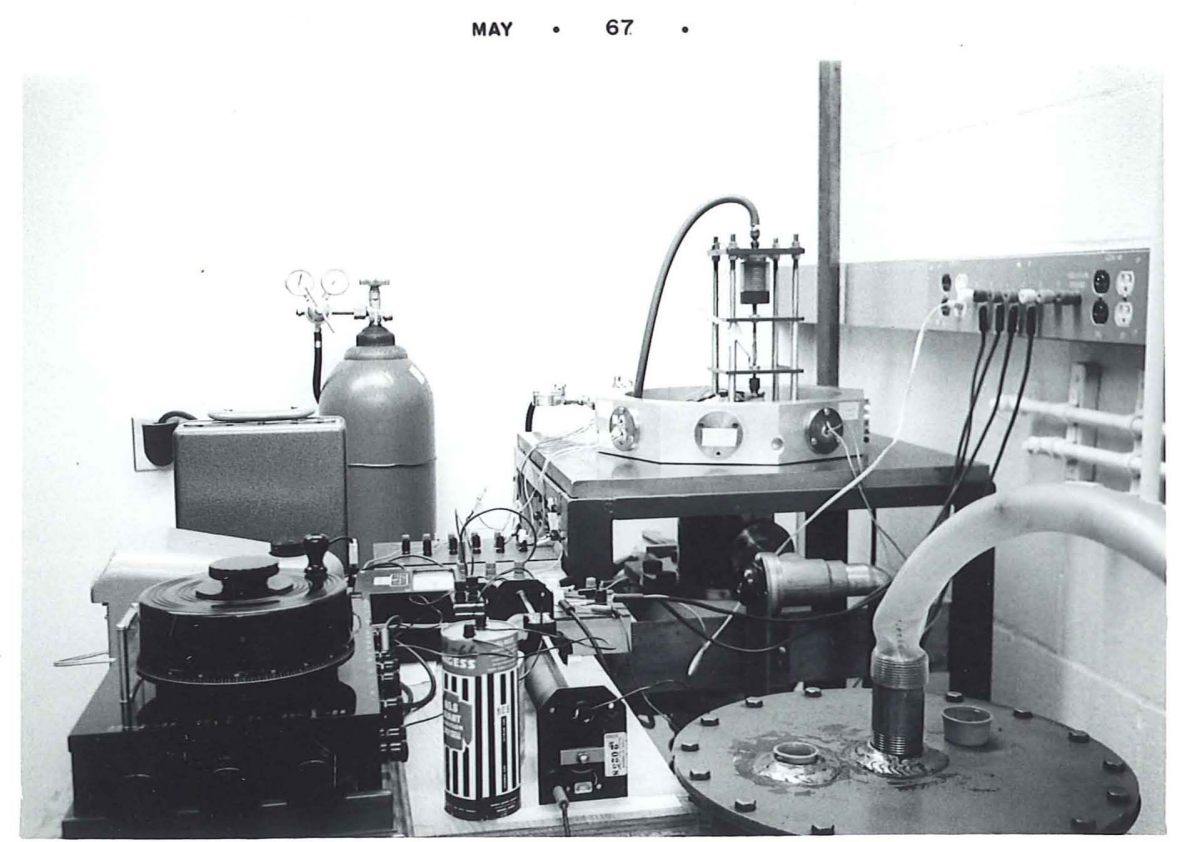

Equipment assembly of experimental apparatus

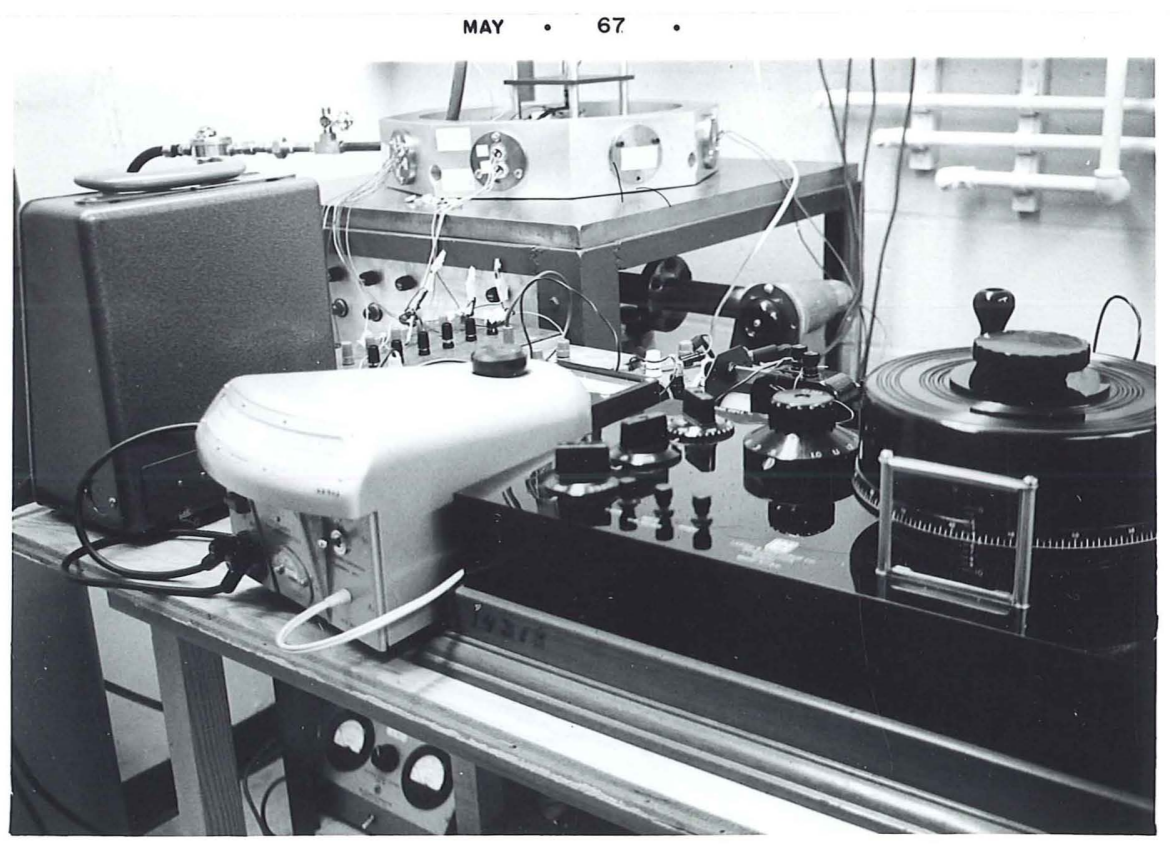

Vacuum gage, below table, galvanometer and potentiometer on table, and vacuum ring and bellows press in the background. 


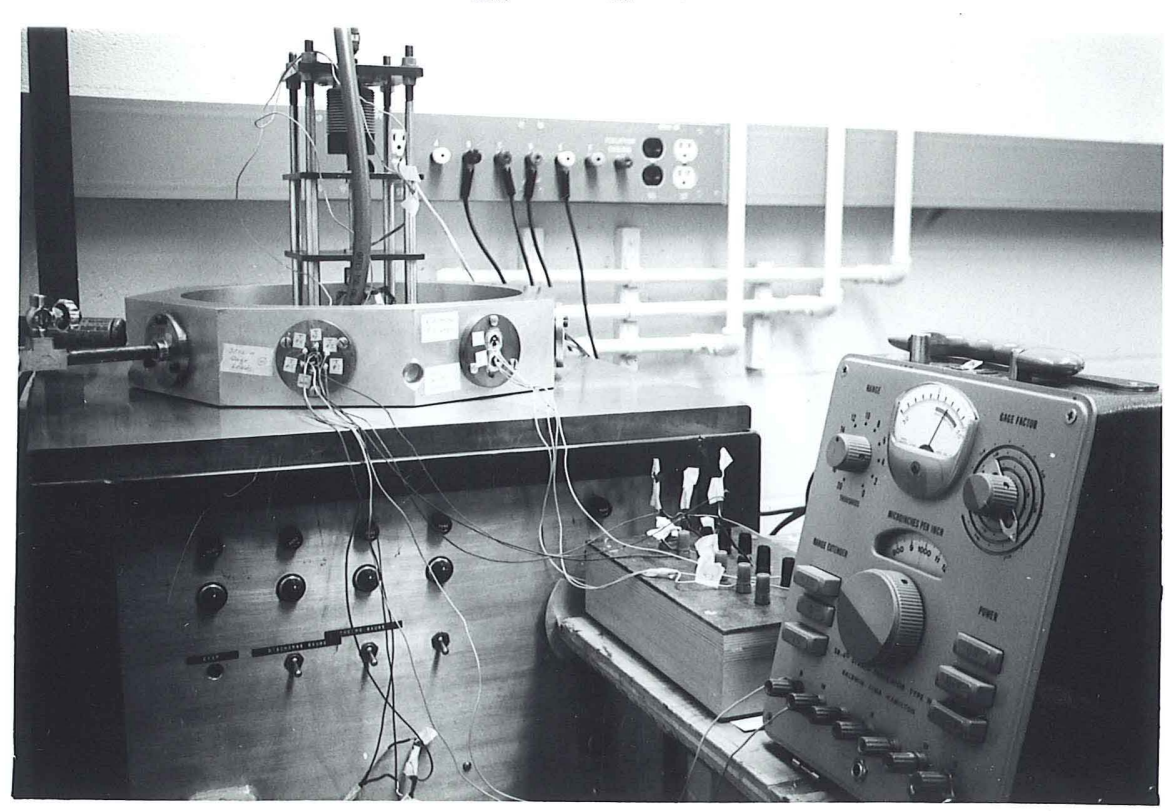

Nitrogen supply pipe to vacuum ring and bellows press, terminal connection box and the strain indicator on the right

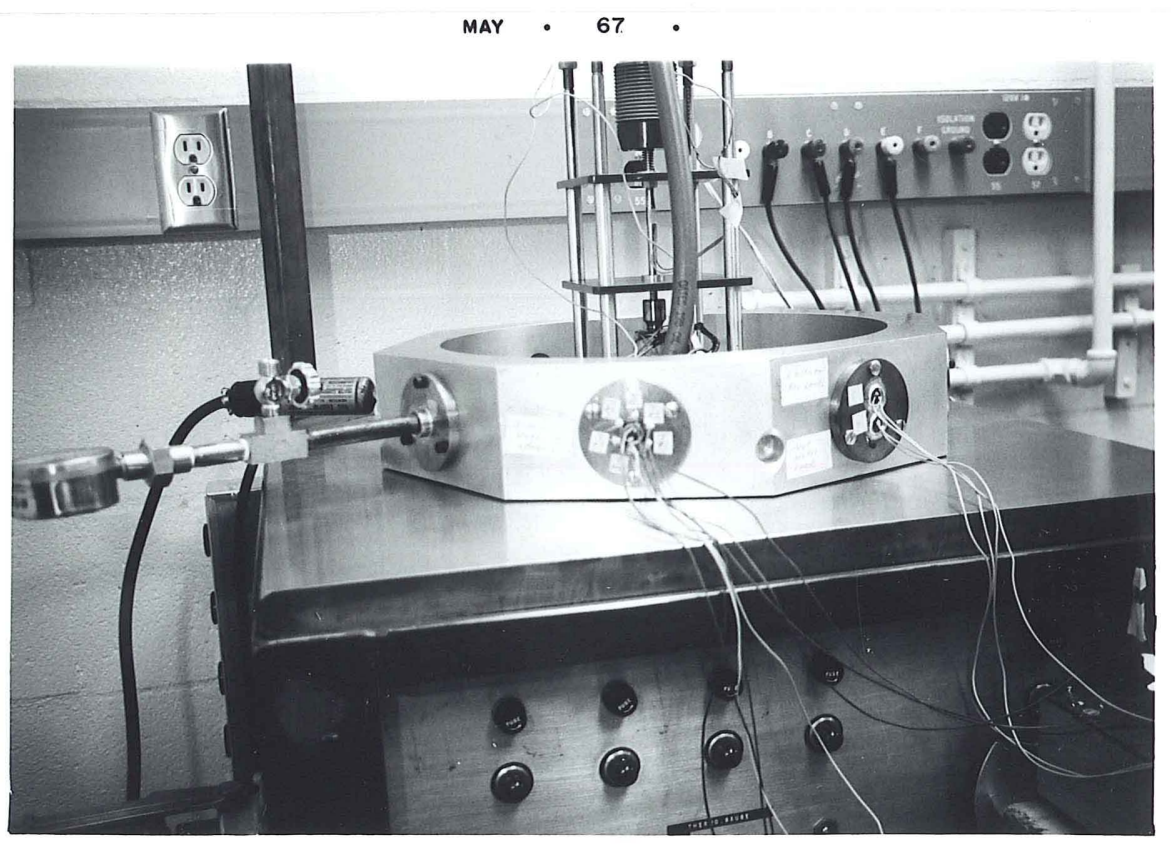

Nitrogen pressure gage and relief valve, vacuum ring, bellows press and platen heater which presses on the wafers 
Fig. 1

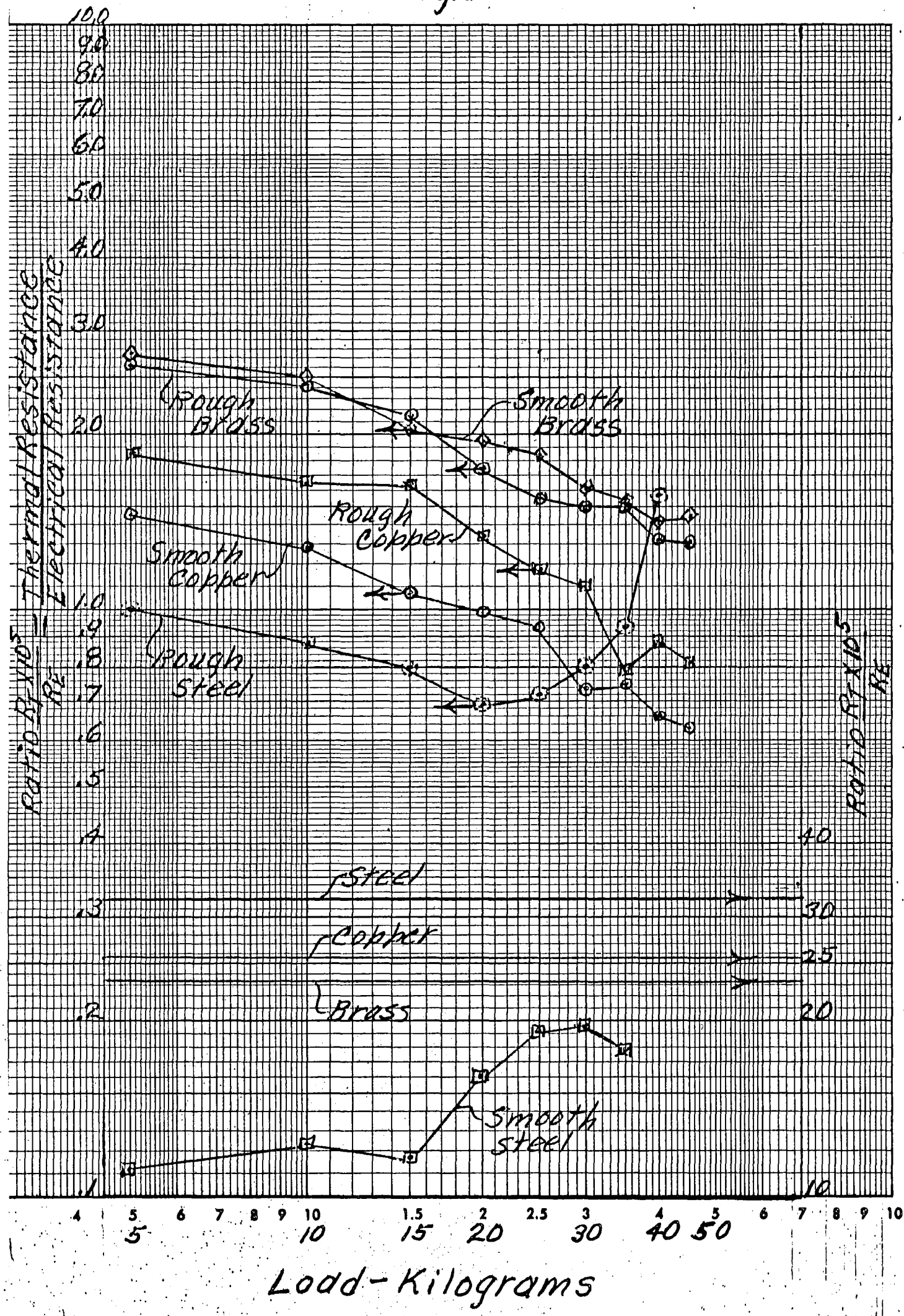


Fig. 2

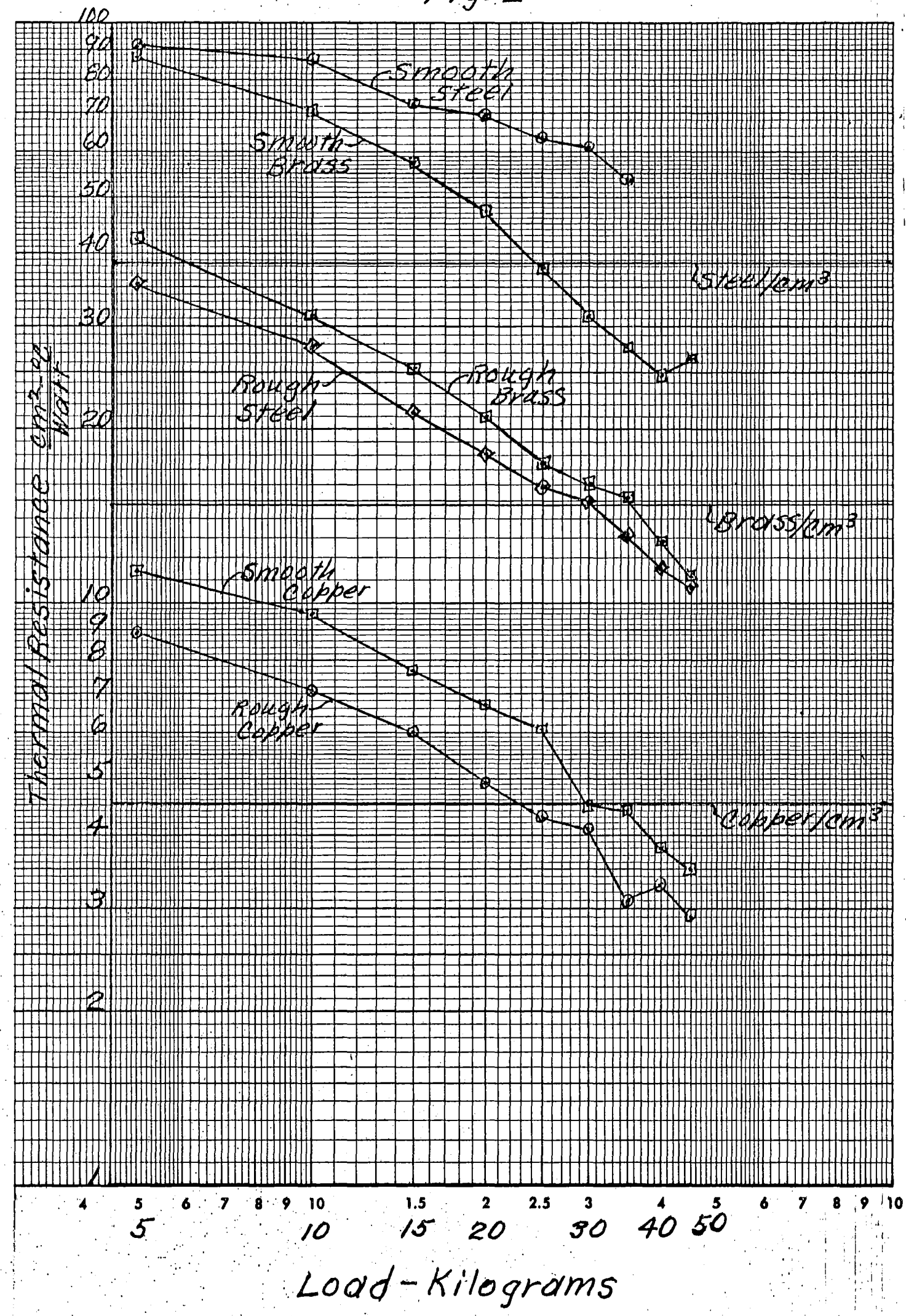


Fig. 3

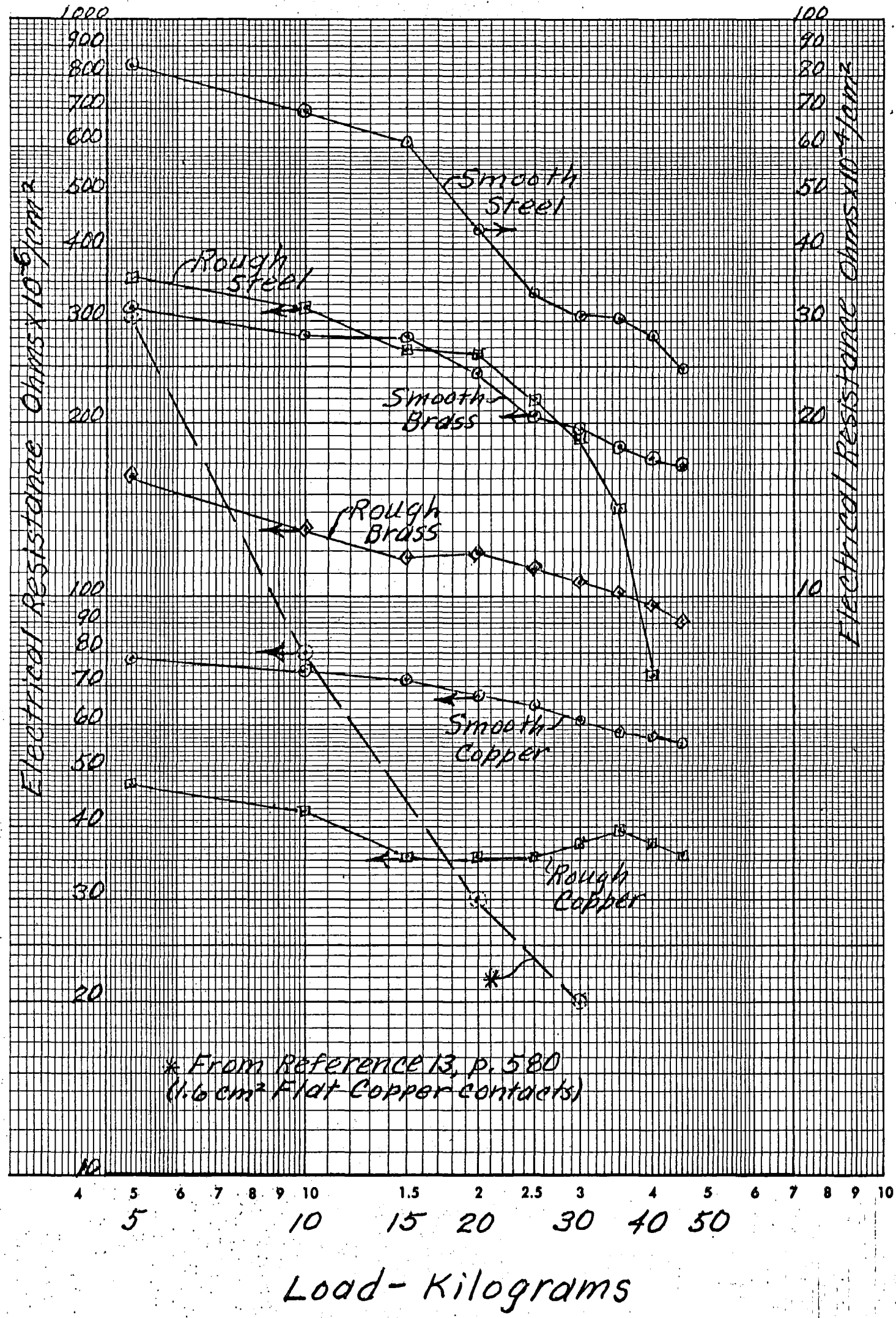

